\title{
The Use of Trading Strategies by Fund Managers: Some First Survey Evidence
}

\author{
Lukas Menkhoff, University of Hannover, Germany \\ and \\ Ulrich Schmidt, University of Hannover, Germany
}

Discussion Paper No. 314

April 2005

ISSN 0949-9962

JEL-Classification: G 23, G 14

Keywords: market efficiency, buy-\&-hold strategy, momentum trading, contrarian strategy, behavioural finance

April 15, 2005

We would like to thank those fund managers who participated in the survey, Michaela Hessmert and Norbert Tolksdorf for helpful comments. Torsten Brozynski and Torben Lütje provided excellent research assistance.

Corresponding: Lukas Menkhoff, Department of Economics, University of Hannover, Königsworther Platz 1, D-30167 Hannover, Germany, menkhoff@gif.uni-hannover.de 


\title{
The Use of Trading Strategies by Fund Managers: Some First Survey Evidence
}

\begin{abstract}
:
Our questionnaire survey finds that most fund managers rely on the strategies of buy-\&-hold, momentum and contrarian trading. These strategies are typically applied mutually. Their use is rooted in the attributes and beliefs of the respective fund managers: buy-\&-hold traders behave fundamentally oriented, risk averse and less (over)confident than others. Momentum traders appear as the least risk averse professionals going aggressively with the trend. Contrarian traders, however, show signs of overconfidence and peculiar risk aversion, both indicating difficulties in successful strategy implementation. The revealed behavioural patterns are not easily reconciled with efficient markets.
\end{abstract}




\section{Introduction}

The debate about efficiency of financial markets is still open (e.g. Malkiel, 2003 and Shiller, 2003). If there is a group that would be able to push markets towards efficiency it is the well educated and well informed group of fund managers. Their transactions have been extensively studied in the recent past but our understanding of their behavioural patterns remains relatively weak. At the same time, there is a growing amount of behavioural finance literature demonstrating the severe limitations of the mainstream "efficient market" paradigm (Hirshleifer, 2001, Barberis and Thaler, 2003, van der Saar, 2004). This motivates the demand for fresh information on fund managers' actions.

We focus here on trading strategies as it has become obvious that the simplified notion of perfectly rational behaviour and the derived buy-\&-hold strategy reflect only part of the fund managers' world. The efficient market paradigm has been challenged by findings that momentum and contrarian strategies which neglect any fundamental information can be profitable, even after consideration of risk premiums. We do not know, however: how important are these trading strategies for fund managers? In which way are they applied and do users share common characteristics? Finally, does real-world application indicate rational behaviour? This study for the first time provides survey evidence on these questions, complementing and extending studies based on transactions data. It finds that all of these strategies are typically used in a complementary manner. In the same instance, the users of momentum, contrarian and buy-\&-hold strategies tend to be characterised by specific attributes. It appears that the implementation of all of these strategies - as revealed by the questionnaire evidence - may be difficult to reconcile with efficient markets.

Recent empirical research has lent considerable credibility to trading strategies which have been used for a long time in financial markets. During the 1970s only the buy-\&-hold strategy seemed to be justified by theoretical and empirical work (see Shiller, 2003). In the 1980s, an influential challenge arose in the work of De Bondt and Thaler (1985), which claimed that a contrarian strategy would be profitable over a time period of several years (see also Lakonishok, Shleifer and Vishny, 1994). Finally, Jegadeesh and Titman (1993) and other studies led to research in the 1990s, proving the remarkable and stable profitability of momentum strategies at horizons of around six months (see the update by Jegadeesh and Titman, 2001). Results for the US markets have been mirrored in many other markets in the world as well (e.g. Grif- 
fin, Ji and Spencer, 2003). ${ }^{1}$ The German market fits into the international evidence by allowing for profitable application of contrarian and momentum trading (Schiereck, De Bondt and Weber, 1999).

This variety in trading approaches seems to be reflected in fund managers' behaviour. The influence of buy-\&-hold considerations is most obvious in the dominating benchmark orientation, where benchmarks are mostly defined as indexes of whole markets or market segments. Explicit contrarian strategies that are profitable in the longer run, however, are less prevalent, possibly due to the rather short-term competition in the fund management industry. A variant is the value-orientation of many fund managers, which is for many proponents another form of buying undervalued assets, i.e. a kind of fundamentally oriented behaviour. The momentum strategy is by contrast quite fashionable, as it promises excess returns as well as an avoidance of positions which are against market trends. It is thus no surprise that effective investments of most US funds reveal elements of momentum trading (Grinblatt, Titman and Wermers, 1995). It is then puzzling, however, how the success of trading strategies reliably found in the literature can be reconciled with the notorious underperformance of the funds which seem to utilize momentum strategies (see e.g. Carhart, 1997, Wermers, 2000). ${ }^{2}$

So, various strategies are applied in practice, but it is not clear how important they are, how they relate to each other, what motivates proponents to rely on these strategies, or whether their application can be reconciled with rational behaviour. Our study aims to shed light on these questions by way of a questionnaire survey that was sent to managers of all professionally run stock and bond funds in Germany at the end of 2002. The sample comprises 117 responses from managers of mutual as well as specialized funds, such as pension funds.

We find that most fund managers rely on all three strategies to some degree, indicating that proponents of certain exclusive trading strategies are rare. However, most professionals have clear preferences regarding these strategies, which can be

\footnotetext{
${ }^{1}$ Note that the evidence on other trading "strategies", such as relying on so-called head-andshoulder rules, may be less favourable (e.g. Lucke, 2003).

2 The fact of lacking satisfactory performance applies to German funds as well (Kempf and Griese, 2003).
} 
related to personal characteristics, information sources and behavioural patterns. ${ }^{3}$ We find these determinants of trading strategies in univariate and multivariate approaches. It appears from our data that all three predetermined trading strategies tend to be preferred by younger and less experienced professionals. Moreover, each trading strategy is clearly related to specific plausible preferences for the kinds of information and is also related to behavioural patterns. Buy-\&-hold traders are comparatively less confident, behave more risk averse and rely strongly on fundamental analysis, motivating to follow a benchmark orientation. By contrast, momentum traders appear as less risk-averse professionals who rely more on non-fundamental information in order to go aggressively with the trend. Contrarian traders, finally, are less senior in fund management, show signs of overconfidence, a tendency towards the disposition effect and some reliance on non-fundamental information. These attributes signal the comparatively greatest difficulties in realizing good investment performance. Overall, the co-existence of less confident buy-\&-hold traders, aggressively trend-following momentum traders and contrarian traders who are distorted in their decision making does not easily conform with the efficient market view.

The remainder of the paper is structured as follows: Section 2 presents the hypotheses to be tested by the questionnaire and Section 3 describes the data from the questionnaire. Results on the use of trading strategies are presented in Section 4, and Section 5 covers information on attributes and beliefs of the users of certain strategies. Section 6 concludes the work.

\section{Hypotheses}

Modern finance literature leaves much room for heterogeneous agents on financial markets, such as the distinction into "arbitrageurs" and "noise traders" (De Long et al., 1990). So what can we expect from users of the different trading strategies? First of all, it is an outstanding question whether the strategies we have addressed by name are really used by different fund managers. The even more fundamental question: are all of these strategies of importance to some fund managers or are there clear favourites, implying that other strategies are of more theoretical importance than practical?

\footnotetext{
${ }^{3}$ We are not aware of any comparable survey evidence for fund managers. Earlier studies on technical analysis-based trading of foreign exchange traders include Taylor and Allen (1992), Cheung and Chinn (2001), Oberlechner (2001) and Gehrig and Menkhoff (2005).
} 
The buy-\&-hold strategy has been understood in interviews (preceding the questionnaire survey) as a benchmark-oriented investment behaviour with deviations from the benchmark mainly based on fundamental analysis. It seems plausible because of three facts that this buy-\&-hold strategy has highest relevance in the professional markets: first, the vast majority of fund managers has market indices as their performance benchmark and thus as reference point. Second, fund managers are aware of the limited chances to outperform markets (see e.g. Carhart, 1997). Third, fundamental analysis is the dominating analytical tool for fund managers (see e.g. Shiller and Pound, 1989, Arnswald, 2001). Some importance can be expected for momentum strategies - to buy (sell) 3-12 months past winners (losers) and hold them for 3-12 months - due to their clear outperformance as shown by the academic literature. According to this reasoning, contrarian strategies could also be of some importance. The latter strategies mean to buy (sell) past losers (winners) and to hold them for a longer period of time, such as years. Regarding the relation of these strategies to each other, earlier research reveals the parallel use of different kinds of strategies for fund managers (Keim and Madhavan, 1995, Badrinath and Wahal, 2002, examine the wider group of institutional investors), a finding being mirrored in foreign exchange markets (e.g. Taylor and Allen, 1992). This leads to our hypotheses one and two:

H1 Among competing trading strategies in fund management, buy-\&-hold is most prominent, being followed by momentum strategy and contrarian strategy.

H2 The three strategies being considered here as well as possible other strategies are mutually applied.

Based on the assumption that a strategy matters at all, the next question to be raised is: who is using it? Can any personal or institutional characteristics be related with certain strategies? According to the efficient market view one might expect that the buy-\&-hold users behave most rationally and are thus those who are comparatively senior in the market, in the sense of having longer experience (being older), more often holding governing positions in fund management or receiving a higher share of variable compensation. By contrast, the application of momentum or contrarian strategies may be related with just the opposite characteristics. ${ }^{4}$

\footnotetext{
${ }^{4}$ We are aware that empirical studies have shown these latter strategies' potential to generate excess returns but we stick to the most conventional expectations.
} 
H3 Users of the buy-\&-hold strategy are associated with signs of seniority whereas momentum and contrarian traders are not.

The associations may even be more self-evident and obvious when it comes to used sources of information. Buy-\&-hold traders can be expected to rely heavily on fundamental facts, whereas momentum and contrarian traders prefer competing sources of information, such as technical analysis.

H4 Users of the buy-\&-hold strategy give fundamentals a high importance as a source of information, whereas momentum and contrarian traders rely more on other sources.

Finally, the body of behavioural finance research has established several "anomalies" in behaviour. If one regards these findings as indications of less than fully rational behaviour, one may also expect that buy-\&-hold traders are less "infected" by these anomalies.

H5 Users of the buy-\&-hold strategy are less prone to anomalies than generally indicated in the behavioural finance literature.

Before we discuss empirical findings on these five hypotheses, the next section describes the methods employed in the survey as well as information gained about the respondents.

\section{Data}

The survey encompassed all relevant fund management companies in Germany between August 15 and December 12, 2002. In total, 64 companies that were believed to manage equity and/or bond funds were approached. Of this total, five companies declared that they did not belong to our target group. Of the remaining 59 companies, 35 participated in the survey, with at least one appropriate questionnaire each. This resulted in a response rate of $59 \%$ concerning participating fund management companies. ${ }^{5}$

To put this figure in perspective, there are several possible viewpoints: in a similarly conceptualized survey of the foreign exchange management by fund managers in Germany, Gehrig and Menkhoff (2004) acquired the participation of 29 companies, resulting in a somewhat lower response rate of $51 \%$. When the Deutsche Bundesbank conducted a survey of the same group of companies, all except one partici-

\footnotetext{
${ }^{5}$ The structure of this response is largely similar to the industry's structure. Our sample is representative in this sense (see Annex 1).
} 
pated (Arnswald, 2001). Other surveys on financial matters that cannot rely on the authority of a central bank - and which are thus better comparable with our approach

- have realized response rates such as $45 \%$ (Shiller and Pound, 1989, for institutional investors), $54 \%$ for foreign exchange dealers in Europe (Oberlechner, 2001) or $8 \%$ regarding foreign exchange dealers in the US (Cheung and Chinn, 2001).

The survey was conducted in several "phases". The first was carried out as a mailed questionnaire in August, allowing for anonymous answers. Thereafter, we followed-up with three more phases of mail, telephone and/or e-mail contacts with fund management companies that were not responding. As some of this communication was done by e-mail which has been forwarded too, unfortunately, we cannot report a useful response rate regarding the number of questionnaires sent and received. $A$ rough estimate capturing only those companies which were basically addressed by paper questionnaire indicates a respective response rate of 30-40\%. Compared with the above mentioned rates, this provides another indicator of acceptance by the target group.

A further measure to ensure reliable responses was the many intensive interviews in advance of the survey. They served to formulate appropriate questions in the language of fund managers and to ensure a common understanding of such broad concepts as momentum trading versus alternatives. Moreover, in later stages the questionnaire was used in a pre-test with several fund managers as a final check of its acceptance and appropriateness. In summary, the individual feedback as well the 117 questionnaires received indicate that the response was useful for our research purposes.

More information on the fund managers can be drawn from the descriptive statistics in Table 1. The typical person is roughly about 35 years old, has 10 years of professional experience, is male, receives a bonus of $25 \%$, holds a university degree, has responsibility in active fund management and manages stocks rather than bonds. This data is consistent with the information from similar surveys in Germany such as Arnswald (2001) or Gehrig and Menkhoff (2004).

\section{$4 \quad$ Evidence on the use of different trading strategies}

This section analyzes the use of trading strategies by asking several questions: are the strategies outlined above really important to practitioners when they have to make a decision on relative importance? Which of these trading strategies is then 
most important? If several strategies are used, are they used exclusively? These are the issues addressed by our hypotheses 1 and 2 .

First, we calculate the mean of the responses given to the question on the intensity of use. Figure 1 presents the mean values as the first bar for each of the four categories distinguished. This figure is $31 \%$ for buy- $\&$-hold, $26 \%$ for the momentum strategy, $29 \%$ for the contrarian strategy and $14 \%$ for others. The three strategies explicitly mentioned are obviously of particular importance and together they account for $86 \%$ of the responses. We can thus give an answer to our first question: it is quite obvious that all three strategies examined are extensively used by practitioners.

To find out more about the use of trading strategies we have analyzed the intensity of use. This ranges from using a certain strategy at all, i.e. giving it more than $0 \%$ (represented as second bar in Figure 1), to preferring a certain strategy to all others, i.e. giving it a higher percentage figure than others plus allocating at least $40 \%$ to this strategy. The outcome of the latter examination is presented in the extreme right-hand bar for each strategy of Figure 1 and shows interesting differences between the use of trading strategies.

Whereas a remarkable $38 \%$ prefer to rely on the buy-\&-hold strategy, just $79 \%$ pay some attention to it. Evidence to the contrary is found for momentum trading: it receives the highest attention among all strategies, but this attention is often comparatively weak. More than $90 \%$ of respondents use momentum strategies to some extent but only $11 \%$ prefer this trading strategy, according to our measure. The contrarian strategy is placed between the two other strategies. Finally, the "others" category receives only minor attention, though it is clear to see that $15 \%$ follow a trading strategy that is not included in our three explicitly mentioned strategies.

Summarizing the evidence regarding hypothesis 1, the answer concerning which strategy is most prominent depends on how the numbers are interpreted. If one relies on the mean value, the three strategies are largely equal. If one focuses on the number of participants paying any attention at all to a strategy, momentum ranks first and buy-\&-hold only third. If one, however, relies on the intensity of use i.e. percentage values of $30 \%$ and more - buy-\&-hold is first and momentum third by a large margin. We conclude that hypothesis 1 is confirmed to some degree, as the buy-\&-hold strategy is preferred by $38 \%$.

The evidence presented in Figure 1 has an obvious implication for hypothesis 2, as respondents in our sample are users not of exclusive but of mutual strategies. As 
an indication, one may add up the values in Figure 1 of those who state that they use a strategy to more than $20 \%$ - the sum of $190 \%$ shows that the vast majority relies on at least two strategies. A further examination of this issue draws on the rank correlation between the strategies distinguished. Here and in all further correlations full information is used by considering all values between 0 and $100 \%$. Table 2 shows the plausible finding that strategies are in general negatively related, which also holds for foreign exchange markets (Taylor and Allen, 1992). It is thus quite interesting that - despite the forced choice involved here - momentum and contrarian strategies are positively related. This indicates that users of these trend-following strategies tend to rely on either both or none. The implication of these several kinds of analyses is that there is support for hypothesis 2 , i.e. evidence contradicts the exclusive use of strategies.

Summing up, all three trading strategies under examination are widely used among fund managers in Germany. Buy-\&-hold trading is the most important strategy, as indicated by the mean value, momentum is the most widespread and momentum and contrarian trading are the only ones whose use is positively correlated. As these very different strategies appear to have importance for professionals' decision making, it would be interesting to know more about the respective users.

\section{$5 \quad$ Evidence on attributes related with trading strategies}

This section is based on the guiding idea that those professionals who rely more on the buy-\&-hold strategy behave more like the arbitrageurs in models with heterogeneous agents (see e.g. De Long et al., 1990). So, they are more senior, more fundamentally oriented and less affected by behavioural anomalies. These three hypotheses of Section 2 will be confronted with our data. Findings for all respondents being reported below hold for subgroups too: stock managers drive the results and bond managers are tentatively in line.

Regarding the seniority of fund managers, a first approximation could be indicated by longer professional experience. This is motivated by the fact that experience helps to build up human capital, which in turn provides better career opportunities. Or to apply the opposite perspective: those who are less successful will be gradually moved out of the market over the years, leading to a kind of survival of the fittest. The rank correlation coefficients between the use of strategies and experience in Table 3 do not support hypothesis 3 , as all the tentative users of trading strategies - i.e. buy- 
\&-hold or momentum or contrarian strategies - show insignificant relations with professional experience whereas only those who rely more on other strategies are significantly positively related.

Also, a second approximation of seniority, i.e. the indicator of a higher share of variable compensation by and large results in similar signs to the above. Adding information from the indicator which seemed to be most promising ex ante, i.e. holding a governing position, such as being head of a team or chief investment officer, does not give significant results and is thus not reported here, although findings are still in line. ${ }^{6}$ Overall, the users of "other strategies" are those who behave as had been expected from the buy-\&-hold fraction, i.e. being senior than others. The contrarians are the opposite pole. Neither buy-\&-hold nor momentum traders can be easily related to any positive or negative indication of seniority. The evidence is thus not in accordance with hypothesis 3 .

As seniority does not seem to be a very clearly discriminating factor regarding our strategies, we turn to hypothesis 4 , relating trading strategies with certain preferred sources of information. The respective question presented in Table 4 allowed for possible answers with varying degrees of agreement. It can be seen that indeed, and exclusively, the more intensive use of a buy-\&-hold trading strategy is significantly related to a greater reliance on fundamentals. The other correlation coefficients are all far from significant, thus hypothesis 4 receives support in this respect. The picture changes, however, when we focus on the reliance of "technical indicators" and "other market participants". Both information sources are not considered in the traditional efficient market framework but analyzed in behavioural finance (e.g. Shiller and Pound, 1989, Taylor and Allen, 1992, Cheung and Chinn, 2001, Gehrig and Menkhoff, 2005). These non-fundamental information sources are not preferred by buy-\&-hold traders, whereas the momentum trading strategy is the only one being significantly positively related to both of them. Contrarians may have at least some sympathy to technical analysis ( $p$-value of 0.128 ). Thus there emerges the picture that users of the buy-\&-hold and momentum strategies form opposite poles with regard to information sources. Users of the contrarian strategy seem to lie between

\footnotetext{
${ }^{6}$ Please note that we cannot use information about fund performance, which may seem another source of interesting information about success, due to the anonymity of our survey. Anonymity is secured in order to stimulate undistorted response by fund managers.
} 
both poles whereas the users of "other strategies" seem to behave eclectically. Consequently, hypothesis 4 receives support.

Building on these findings, one could imagine that the users of different strategies do not only prefer different sources of information but also show different behavioural patterns. First of all, we asked about the preference towards taking profits in case of unexpected liquidity demand, a question that aims to identify the well established disposition effect (see Shefrin and Statman, 1985, Odean, 1998, Shapira and Venezia, 2001). The response given in Table 5 reveals that contrarians and tentative buy-\&-hold users give comparatively stronger answers being consistent with the disposition effect. As this could be related to the general attitude towards risk taking, we further asked about the degree of risk acceptance in a financial lottery environment. The second item in Table 5 shows that buy- $\&$-hold traders reveal more risk averse preferences whereas momentum traders behave in an opposite manner. Both questions taken together provide the picture that the users of buy-\&-hold as well as contrarian strategies show a similarity which seems surprising when compared to earlier findings: the behaviour of both kinds of fund managers is different from other fund managers as they reveal a stronger disposition effect and risk aversion. Here, the opposite pole is formed by the users of the momentum strategy. Momentum traders reveal a significantly lower degree of risk aversion than other fund managers. ${ }^{7}$

It seems to be an almost obvious speculation whether momentum traders in particular are thus a group showing greater signs of overconfidence (Klayman et al., 1999, Odean, 1999). When we ask for a self-assessment of relative performance, we are not interested in the outright answer but in the relation of optimistic selfassessment to the preference for certain strategies. Item 3 in Table 5 gives a somewhat surprising result: users of the buy-\&-hold strategy hold rather modest views on their own performance, whereas contrarians express considerable self-confidence, as do users of other strategies.

What is interesting in itself becomes even more revealing when compared to the more "objective" indicators of seniority discussed in connection with Table 3. Users of other strategies seemed to be - if anything at all - a group of comparatively senior fund managers, which conforms with their self-assessment. Users of the buy-

\footnotetext{
${ }^{7}$ It would be preferable to test behavioural patterns, such as risk aversion, by several questionnaire items to increase validity. However, we were asking heavily time-constrained fund
} 
\&-hold strategy cannot be related to seniority and are modest, possibly too modest. The clear contrast is provided by users of contrarian strategies, who show the fewest signs of seniority but strongly believe in their superiority - if there is any overconfidence, this is the group revealing it. For information, users of momentum strategy are neutral in both categories of interest here.

Finally, in search of a possible motivation for momentum trading, we asked for an evaluation of possible selective representation of news by others. This confirmation bias of other market participants may inform whether their own strategy intends to exploit distorted behaviour in the market. It is shown by item 4 in Table 5 that only momentum traders tend to hold this kind of belief.

Summarizing on hypothesis 5 , stating that the users of the buy-\&-hold strategy would be less affected by anomalies found in the behavioural finance literature, the evidence provides only some support. It can be said, in addition, that those who show the greatest affinity to anomalies seem to be users of the contrarian strategy.

In an effort to develop a coherent set of motivations favouring the use of certain trading strategies, the information underlying Tables 3 to 5 is now analyzed in a multivariate setting. As the dependent variables are censored to a minimum of $0 \%$ and a maximum of $100 \%$, we apply two-limit Tobit regressions. Results shown in Table 6 strengthen the impression from the above presented univariate regressions. ${ }^{8}$ The number of significant coefficients is about the same, most of them being identical in both approaches. Not any single significant coefficient has changed sign. The major change that occurred is a substitution in the risk items: general risk aversion is more significant in the univariate approach but the disposition effect in the multivariate approach. Comparing the relative importance of determinants, coefficients can be directly interpreted as, first, the dimension of variables is about the same, and, second, the Tobit regression allows for a linear interpretation inside the "borders" which does plausibly apply here. Keeping this in mind, evidence is somewhat differently emphasized, in particular since the information sources (see Table 4) receive more attention than before. ${ }^{9}$ Thus, some comments may be warranted:

managers (and not students as in most of these experiments or survey studies). As we were aiming for a high response rate, we restricted ourselves to a parsimonious questionnaire.

${ }^{8}$ To check robustness of findings, we have excluded insignificant variables one by one but findings do not change much.

${ }^{9}$ An ordered probit approach as run by Keim and Madhavan, 1995, Marston and Craven, 1998, confirms the findings (but cannot provide a result for the "other strategies" which is too 
- $\quad B u y-\&-h o l d$ traders (i.e. those who tend towards buy-\&-hold strategies) appear in the multivariate approach as being clearly defined by their attitude towards information sources. They rely on fundamental analysis, as in the univariate approach, but now they sharpen their profile as they also tend to reject reliance on other market participants. Moreover, they are quite risk averse, although emphasis shifts from the general risk aversion (see Table 5) to the loss aversion here being revealed by their strong disposition effect. This corresponds to an attitude of going along with the market. If the risk of a fund manager is mainly diverting from others, this strategy is a rational choice for risk averse and less (over)confident fund managers (e.g. Scharfstein and Stein, 1990).

- By contrast, momentum traders are the only group that is clearly less risk averse - in the sense of less disposition effect - than the average of fund managers. Their second clearly revealed characteristic is the reliance on nonfundamental sources of information. Both less risk aversion and the use of nonfundamental information show up nicely in the multivariate and univariate approaches as well. Interestingly, the belief that others pay attention to confirmatory information becomes unimportant in the multivariate setting.

- Contrarians are the single group in Table 6 that believes itself to be clearly better than other fund managers. ${ }^{10}$ This stands in contrast to their rather weak indicators of seniority. In the multivariate approach they appear as being less experienced (in the univariate approach they showed lower bonus payments). High self-esteem plus low seniority may indicate overconfidence. In contrast to the univariate regressions (Table 5), their comparatively strong risk aversion disappears here. Instead, a somewhat questionable reliance on fundamental as well as technical analysis is revealed in Table 6 which may be speculatively interpreted as another form of risk-aversion, i.e. claiming to do everything at the same time. ${ }^{11}$ In any case, risk aversion rather leads to going with the trend than against it. So, a peculiar form of risk aversion - such as the disposition effect shown in Table 5 - is necessary to motivate contrarian trading. If such distorted

often given $0 \%$ and thus does not generate enough variance). The only difference compared with the Tobit approach is that the technical indicators variable in the contrarian regression loses significance ( $p$-value of 0.124).

${ }^{10}$ To be precise, the question here is not on the existence of overconfidence but on its degree compared to others. 
behavioural patterns exist, they may complement overconfidence as the undisputed determinant. This is a dangerous set of ingredients because the disposition effect, as well as overconfidence, generates underperformance in the market (see Odean, 1998, 1999).

- Finally, the group that is comparatively neutral in its risk attitude is the users of other strategies. This group, which is characterized by some attributes of seniority, could be the one which performs the role of fundamentally oriented arbitrageurs. In fact, however, they use information sources in an eclectic manner, just as their unspecified "other strategy" implies. ${ }^{12}$

\section{Conclusions}

This paper provides - according to the best of our knowledge - the first survey information on the use of three popular trading strategies in fund management, i.e. buy-\&-hold, momentum and contrarian trading. We analyze the responses from fund managers of German mutual and pension funds who seem to be largely representative of the market.

We do find that all of the strategies mentioned above are of significance for fund managers. We find moreover that the buy-\&-hold strategy is the most important one, whereas momentum trading in particular is widely used but less relied on. Finally, it is only momentum and contrarian trading that seem to be used in a complementary fashion, whereas all other signs of correlations between the intensity of use are negative.

Taking the intensity of use as a preference for a particular strategy, this raises the question about the attitudes and beliefs of its users. In this respect, we analyze three fields: indicators of seniority in the market, reliance on specific sources of information and behavioural patterns. We find interesting relations that help to shape an idea of the respective types of traders: buy-\&-hold traders rely on the most accepted fundamental analysis, are comparatively risk averse and not (overly) selfconfident, which motivates them to behave in accordance with their benchmark, i.e. usually the market. Contrarians are overconfident, influencing them to hold on

\footnotetext{
${ }^{11}$ One may also see this as a kind of overconfidence as these respondents seem to feel better able than others to choose discretionarily between different analytical instruments.

${ }^{12}$ From a methodological point of view it is interesting to note that the use of "other strategies" is the only trading strategy being not related to any attribute (than experience). This provides indirect evidence that the behavioral substantiation of trading strategies is real.
} 
against market trends. Moreover, there are indications of the disposition effect for this group, increasing their tendency to go against the market. Momentum traders are least risk averse and rely on tentatively trend-following technical indicators as well as on other market participants. They thus seem to go aggressively with the market. Finally, those following other strategies fit best into the expected characteristics of arbitrageurs but, unfortunately, their sources of information are eclectic.

Overall, the evidence corresponds nicely with facts of other approaches being taken in the literature. ${ }^{13}$ It has been learned from this earlier work that there are strong incentives to go rationally with the market, but also to differentiate one's own behaviour, and that most funds lag behind the market's performance. We might want to speculate that those who are characterized as buy-\&-hold traders form the herd of the market. Momentum traders have some chances as they are less risk averse. However, this force is not really strong in the market when it comes to the bottom-line in decision making. Contrarians, as they are revealed in our sample, are probably not the long-run arbitrageurs to outwit the market but may tend to perform even worse than the crowd. Finally, there is a smaller group of experienced "others" who might be able to perform the role of rational arbitrageurs but do not seem to behave like these arbitrageurs (see also De Long et al., 1990). Possibly, this is a sign that rational speculators also take the risk from noise traders into account. There is no clear indication, however, that these findings would bring about market efficiency.

In summary, the results of this survey complement other findings in financial markets which do not correspond easily to the expectation of efficient markets (recently e.g. Shiller, 2003). Trading strategies seem to be widespread among fund managers and there is little evidence that they would generate excess returns in practice (Malkiel, 2003). Evidence suggests, moreover, that the use of trading strategies might be related to behavioural anomalies. These findings demand further research into examining links between the behavioural patterns of fund managers, the use of trading strategies and their impact on fund performance as well as market efficiency.

\footnotetext{
13 The survey approach is rather unconventional in the finance literature but has certain methodological advantages (see van der Sar, 2004, 435).
} 


\section{References}

Arnswald, Torsten (2001), Investment Behaviour of German Equity Fund Managers, An Exploratory Analysis of Survey Data, Deutsche Bundesbank Discussion Paper 08/01, Frankfurt.

Badrinath, Swaminathan G. and Sunil Wahal (2002), Momentum Trading by Institutions, Journal of Finance, 57:6, 2449-2478.

Barberis, Nicholas and Richard Thaler (2003), A Survey of Behavioral Finance, in: G.M. Constantinidis, M. Harris and R.M. Stulz (eds.), Handbook of the Economics of Finance, Vol. 1B, Amsterdam et al.: Elsevier, 1051-1121.

Carhart, Mark M. (1997), On Persistence in Mutual Fund Performance, Journal of Finance, 52:1, 57-82.

Cheung, Yin-Wong and Menzie D. Chinn (2001), Currency Traders and Exchange Rate Dynamics: A Survey of the US Market, Journal of International Money and Finance, 20, 439-471.

De Bondt, Werner F.M. and Richard H. Thaler (1985), Does the Stock Market Overreact?, Journal of Finance, 40, 793-808.

De Long, J. Bradford, Andrei Shleifer, Lawrence Summers and Robert J. Waldmann (1990), Noise Trader Risk in Financial Markets, Journal of Political Economy, 98:4, 703-748.

Gehrig, Thomas and Lukas Menkhoff (2004), The Use of Flow Analysis in Foreign Exchange: Exploratory Evidence, Journal of International Money and Finance, 23, 573-594.

Gehrig, Thomas and Lukas Menkhoff (2005), Extended Evidence on the Use of Technical Analysis in Foreign Exchange, International Journal of Finance and Economics, forthcoming.

Griffin, John M., Susan Ji and J. Spencer Martin (2003), Momentum Investing and Business Cycle Risk: Evidence from Pole to Pole, Journal of Finance, 58:6, 2515-2547.

Grinblatt, Mark, Sheridan Titman and Russ Wermers (1995), Momentum Investment Strategies, Portfolio Performance, and Herding: A Study of Mutual Fund Behavior, American Economic Review, 85:5, 1088-1105.

Hirshleifer, David (2001), Investor Psychology and Asset Pricing, Journal of Finance, $56: 4,1533-1597$. 
Jegadeesh, Narasimhan and Sheridan Titman (1993), Returns to Buying Winners and Selling Losers: Implications for Stock Market Efficiency, Journal of Finance, 48:1, 65-91.

Jegadeesh, Narasimhan and Sheridan Titman (2001), Profitability of Momentum Strategies: An Evaluation of Alternative Explanations, Journal of Finance, 56, 699-720.

Keim, Donald B. and Ananth Madhavan (1995), Anatomy of the Trading Process, Empirical Evidence on the Behavior of Institutional Traders, Journal of Financial Economics, 37, 371-398.

Kempf, Alexander and Knut Griese (2003), Lohnt aktives Fondsmanagement aus Anlegersicht?, Zeitschrift für Betriebswirtschaft, 73:2, 201-224.

Klayman, Joshua, Jack B. Soll, Claudia González-Vallejo and Sema Barlas (1999), Overconfidence: It Depends on How, What and Whom You Ask, Organizational Behavior and Human Decision Processes, 79:3, 216-247.

Lakonishok, Josef, Andrei Shleifer and Robert W. Vishny (1994), Contrarian Investment, Extrapolation, and Risk, Journal of Finance, 49:5, 1541-1578.

Lucke, Bernd (2003), Are Technical Trading Rules Profitable? Evidence for Headand-Shoulder Rules, Applied Economics, 35:1, 33-40.

Malkiel, Burton G. (2003), Passive Investment Strategies and Efficient Markets, European Financial Management, 9:1, 1-10.

Marston, Claire L. and Barrie M. Craven (1998), A Survey of Corporate Perceptions of Short-termism among Analysts and Fund Managers, European Journal of Finance, 4, 233-256.

Oberlechner, Thomas (2001), Importance of Technical and Fundamental Analysis in the European Foreign Exchange Market, International Journal of Finance and Economics, 6:1, 81-93.

Odean, Terrance (1998), Are Investors Reluctant to Realize Their Losses?, Journal of Finance, 53, 1775-1798.

Odean, Terrance (1999), Do Investors Trade Too Much?, American Economic Review, 89:5, 1279-1298.

Scharfstein, David S. and Jeremy C. Stein (1990), Herd Behavior and Investment, American Economic Review, 80:3, 465-479.

Schiereck, Dirk, Werner De Bondt and Martin Weber (1999), Contrarian and Momentum Strategies in Germany, Financial Analysts' Journal, 55:6, 104-116. 
Shapira, Zur and Itzhak Venezia (2001), Patterns of Behavior of Professionally Managed and Independent Investors, Journal of Banking and Finance, 25, 1573-1587.

Shefrin, Hersh and Meir Statman (1985), The Disposition to Sell Winners Too Early and Ride Losers Too Long: Theory and Evidence, Journal of Finance, 40, 777-790.

Shiller, Robert J. (2003), From Efficient Markets Theory to Behavioral Finance, Journal of Economic Perspectives, 17:1, 83-104.

Shiller, Robert J. and John Pound (1989), Survey Evidence on Diffusion of Interest and Information Among Investors, Journal of Economic Behavior and Organization, 12:1, 47-66.

Taylor, Mark P. and Helen Allen (1992), The Use of Technical Analysis in the Foreign Exchange Market, Journal of International Money and Finance, 11, 304314.

van der Sar, Nico L. (2004), Behavioral Finance: How Matters Stand, Journal of Economic Psychology, 25:3, 425-444.

Wermers, Russ (2000), Mutual Fund Performance: An Empirical Decomposition into Stock-Picking Talent, Style, Transactions Costs, and Expenses, Journal of Finance, 55:4, 1655-1695. 
TABLE 1. Descriptive statistics on the survey respondents

\begin{tabular}{|c|c|c|c|c|c|c|}
\hline Item asked & & $\operatorname{Rep}$ & onses (in & percentag & & Number of \\
\hline Age (in years) & $<35$ & $50.9 \%$ & 35-45: & $46.5 \%$ & $>45: \quad 2.6 \%$ & 114 \\
\hline $\begin{array}{l}\text { Profess. } \\
\text { experience }\end{array}$ & $<5$ & $22.3 \%$ & 5-15: & $59.8 \%$ & $>15: 17.9 \%$ & 112 \\
\hline Gender & & male: & $92.1 \%$ & female: & $7.9 \%$ & 114 \\
\hline $\begin{array}{l}\text { Share of variable } \\
\text { compensation }\end{array}$ & & mean: & $25.8 \%$ & std. dev.: & 14.5 & 85 \\
\hline University degree & & yes: & $84.8 \%$ & no: & $15.2 \%$ & 112 \\
\hline Governing position & & yes: & $36.9 \%$ & no: & $63.1 \%$ & 103 \\
\hline $\begin{array}{l}\text { Kind of fund man- } \\
\text { agement (primarily) }\end{array}$ & & active: & $93.7 \%$ & passive: & $6.3 \%$ & 111 \\
\hline $\begin{array}{l}\text { Kind of securities } \\
\text { managed }^{*}\end{array}$ & & stocks: & $66.5 \%$ & bonds: & $33.5 \%$ & 115 \\
\hline
\end{tabular}

* $4.2 \%$ of the respondents managed stocks and bonds to the same degree. These respondents were added with half weight to stocks as well as bonds, so that the sum adds up to $100 \%$. 


\section{FIGURE 1. The use of several trading strategies}

Question: "How intensively do you use several strategies? Please, allocate 100\%." Answering categories: $" . . . . . \%$ Momentum strategy, ...... \% Contrarian strategy (Value strategy), ..... \% Buy-\&-Hold strategy, $\%$ Others"

\section{Buy-\&-Hold}

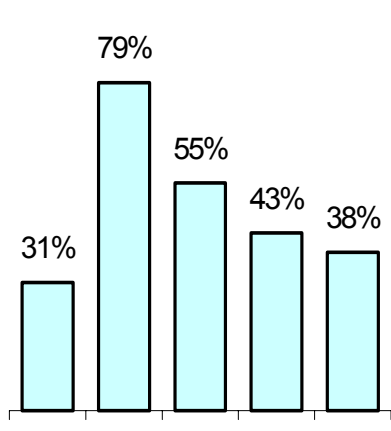

mean $>0 \% \geq 20 \% \geq 30 \%$ pref.

\section{Momentum}

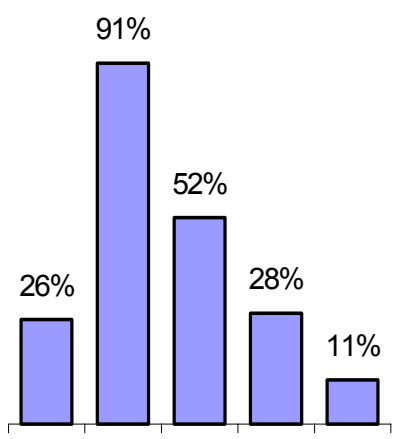

mean $>0 \% \geq 20 \% \geq 30 \%$ pref.
Contrarian

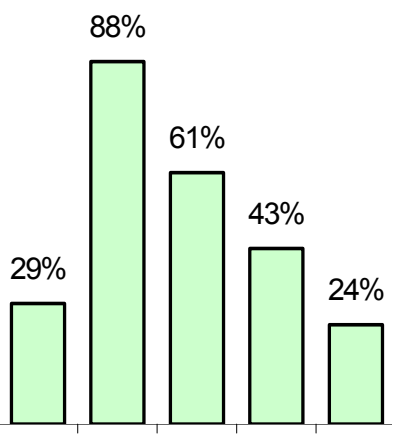

mean $>0 \% \geq 20 \% \geq 30 \%$ pref.
Others

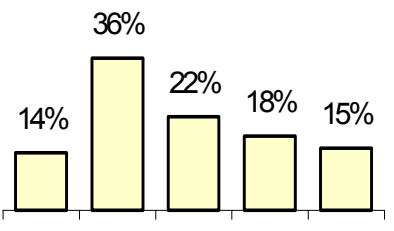

mean $>0 \% \geq 20 \% \geq 30 \%$ pref.

Note: The mean value represents the average intensity of use on the four answering categories. The other percentage figures give shares of answers in relation to the total number of 108 responds on this question. For example, the first such percentage figure given says that $79 \%$ of all respondents allocate more than $0 \%$ to the buy-\&-hold strategy. The last bar on "preferred" gives the share which unanimously prefers this certain strategy to all others. Regarding these preferred trading strategies, there remain $12 \%$ of respondents who do not voice a clear preference but choose two or more strategy as equally high ranking, such as $40 \%-40 \%-20 \%-0 \%$.

TABLE 2. Correlation coefficients on the use of trading strategies

\begin{tabular}{lcccc}
\hline Strategies & $\begin{array}{c}\text { Buy-\&-Hold } \\
\text { strategy }\end{array}$ & $\begin{array}{c}\text { Momentum } \\
\text { strategy }\end{array}$ & $\begin{array}{c}\text { Contrarian } \\
\text { strategy }\end{array}$ & $\begin{array}{c}\text { Other } \\
\text { strategies }\end{array}$ \\
Buy-\&-Hold & - & $-0.515^{* * *}$ & $-0.355^{* * *}$ & $-0.449^{* *}$ \\
Momentum & - & $0.344^{* * *}$ & $-0.202^{* *}$ \\
Contrarian & & & - & $-0.309^{* * *}$ \\
\hline
\end{tabular}

This table is based on 108 responses. For the exact question see Figure 1.

Stars refer to level of significance of the Spearman rank correlation coefficient between the use of momentum strategy and the use of contrarian strategy etc., ${ }^{*}: 10$ per cent, ${ }^{* *}: 5$ per cent. ${ }^{* * *}: 1$ per cent 
TABLE 3. Persons' characteristics and trading strategies

\begin{tabular}{lcccc}
\hline $\begin{array}{l}\text { Characteristics } \\
\text { [number] }\end{array}$ & \multicolumn{2}{c}{ Spearman rank correlation coefficients (and p-value) } \\
& $\begin{array}{c}\text { Buy-\&-Hold } \\
\text { strategy }\end{array}$ & $\begin{array}{c}\text { Momentum } \\
\text { strategy }\end{array}$ & $\begin{array}{c}\text { Contrarian } \\
\text { strategy }\end{array}$ & $\begin{array}{c}\text { Other } \\
\text { strategies }\end{array}$ \\
$\begin{array}{l}\text { Longer professional } \\
\text { experience [104] }\end{array}$ & -0.120 & -0.007 & -0.006 & $0.251^{* * *}$ \\
Higher share of variable & $(0.227)$ & $(0.943)$ & $(0.956)$ & $(0.010)$ \\
compensation [80] & 0.127 & -0.044 & $-0.186^{*}$ & 0.042 \\
& $(0.262)$ & $(0.697)$ & $(0.099)$ & $(0.711)$
\end{tabular}

Note: The exact questions and response categories are given in Table 1 and Figure 1. There is no statistically significant relation of trading strategies with the following characteristics: governing position, gender, university degree and kind of securities managed. The coefficients for age are very similar to those for experience.

Stars refer to level of significance, ${ }^{*}: 10$ per cent, ${ }^{* *}: 5$ per cent. ${ }^{* * *}: 1$ per cent

\section{TABLE 4. Information sources and trading strategies}

Request: "Please, asses the importance of the following sources of information for you."

Answering categories: "Fundamental facts about the company/market", "Technical indicators", "Colleagues from the own company", "Other market participants". 6 answering categories from "high importance" (coded as 1) to "no importance" (coded as 6).

Characteristics [number]

\section{Spearman rank correlation coefficients (and p-value)}

\begin{tabular}{|c|c|c|}
\hline $\begin{array}{l}\text { 3uy-\&-Hold } \\
\text { strategy }\end{array}$ & $\begin{array}{c}\text { Momentum } \\
\text { strategy }\end{array}$ & $\begin{array}{c}\text { Contrarian } \\
\text { strategy }\end{array}$ \\
\hline
\end{tabular}

\begin{tabular}{lcccc} 
Less fundamental & $-0.178^{*}$ & 0.104 & -0.080 & 0.122 \\
facts [107] & $(0.066)$ & $(0.284)$ & $(0.412)$ & $(0.210)$ \\
Less technical & 0.150 & $-0.281^{* * *}$ & -0.149 & 0.056 \\
indicators [106] & $(0.124)$ & $(0.003)$ & $(0.128)$ & $(0.572)$ \\
Less market & 0.073 & $-0.191^{* *}$ & 0.021 & 0.077 \\
participants [107] & $(0.457)$ & $(0.048)$ & $(0.830)$ & $(0.432)$ \\
\hline
\end{tabular}

Note: The relation of trading strategies with "colleagues from the own company" are far from being significant.

Stars refer to level of significance, ${ }^{*}: 10$ per cent, ${ }^{* *}: 5$ per cent. ${ }^{* * *}: 1$ per cent 


\section{TABLE 5. Behavioural patterns and trading strategies}

Statement: "I prefer to take profits when I am confronted with unexpected liquidity demands."

6 answering categories from "complete approval" (coded as 1) to "complete contradiction" (coded as 6).

Question: "Imagine someone offers you a bet and the odds are fifty-fifty. You will have to pay $€ 100$, if you lose. What would be the minimum amount to win to lure you into accepting the bet?" Answer " $€ "$.

Question: "How do you evaluate your own performance compared to other asset managers?" Answering categories: "much better (coded as 1), slightly better (coded as 2), equally good (coded as 3 ), slightly worse (coded as 4), much worse" (coded as 5).

Statement: "My colleagues pay particular attention to confirmatory news/information after having made an investment decision". 6 answering categories from "complete approval" (coded as 1) to "complete contradiction" (coded as 6).

Characteristics [number]

I do not prefer to

take profits [107]

Higher minimum

amount to win [103]

Worse performance

than others [105]

No attention to

confirmatory

information [106]

\section{Spearman rank correlation coefficients (and p-value)}

$\begin{array}{ccc}\begin{array}{c}\text { Buy-\&-Hold } \\ \text { strategy }\end{array} & \begin{array}{c}\text { Momentum } \\ \text { strategy }\end{array} & \begin{array}{c}\text { Contrarian } \\ \text { strategy }\end{array}\end{array}$

Other strategies
$-0.154$
$-0.036$
$-0.246^{* *}$
0.158
$(0.113)$
$(0.716)$
(0.011)
(0.104)

$\begin{array}{lll}0.189^{*} & -0.216^{* *} & 0.134 \\ (0.055) & (0.028) & (0.177)\end{array}$

$-0.060$ (0.548)

$\begin{array}{llcc}0.334^{* * *} & -0.131 & -0.266^{* * *} & -0.211^{* *} \\ (0.001) & (0.183) & (0.006) & (0.031)\end{array}$

$-0.012$

$-0.217^{* *}$

$-0.007$

0.028

$(0.903)$

(0.026)

(0.776)

Stars refer to level of significance, ${ }^{*}: 10$ per cent, ${ }^{* *}: 5$ per cent. ${ }^{* * *}: 1$ per cent 
TABLE 6. Multivariate determinants of trading strategies

\begin{tabular}{lcccc}
\hline Characteristics & \multicolumn{3}{c}{ TOBIT regression coefficients (and p-value) } \\
& $\begin{array}{c}\text { Buy-\&-Hold } \\
\text { strategy }\end{array}$ & $\begin{array}{c}\text { Momentum } \\
\text { strategy }\end{array}$ & $\begin{array}{c}\text { Contrarian } \\
\text { strategy }\end{array}$ & $\begin{array}{c}\text { Other } \\
\text { strategies }\end{array}$ \\
Intercept & $-53.116^{* *}$ & $79.076^{* * *}$ & $84.722^{* * *}$ & $-88.294^{* *}$ \\
& $(0.027)$ & $(0.000)$ & $(0.000)$ & $(0.043)$ \\
Longer professional & 0.951 & -3.056 & $-4.269^{* *}$ & $15.593^{* *}$ \\
experience & $(0.785)$ & $(0.103)$ & $(0.015)$ & $(0.018)$ \\
Higher share of & $0.609^{* *}$ & -0.162 & -0.108 & -0.297 \\
variable compensation & $(0.027)$ & $(0.283)$ & $(0.443)$ & $(0.547)$ \\
Less fundamental & $-6.550^{*}$ & 3.181 & $-4.296^{* *}$ & 8.181 \\
facts & $(0.089)$ & $(0.147)$ & $(0.035)$ & $(0.233)$ \\
Less technical & 3.896 & $-6.969^{* * *}$ & $-2.554^{*}$ & $10.629^{* *}$ \\
indicators & $(0.153)$ & $(0.000)$ & $(0.082)$ & $(0.036)$ \\
Less market & $9.202^{* * *}$ & $-6.895^{* * *}$ & -0.543 & 3.944 \\
participants & $(0.009)$ & $(0.001)$ & $(0.766)$ & $(0.522)$ \\
I do not prefer to & $-8.096^{* * *}$ & $4.305^{* * *}$ & -0.455 & -0.027 \\
take profits & $(0.004)$ & $(0.003)$ & $(0.740)$ & $(0.996)$ \\
Higher minimum & -0.007 & -0.002 & -0.001 & $0.009^{*}$ \\
amount to win & $(0.300)$ & $(0.305)$ & $(0.413)$ & $(0.094)$ \\
& & & & \\
Worse performance & $23.584^{* * *}$ & -4.813 & $-10.889^{* * *}$ & -7.924 \\
than others & $(0.000)$ & $(0.116)$ & $(0.000)$ & $(0.447)$ \\
No attention to con- & 1.104 & -1.262 & 2.284 & -5.578 \\
firmatory information & $(0.761)$ & $(0.542)$ & $(0.239)$ & $(0.421)$ \\
\hline Adjusted $R^{2}$ [number] & $0.2098[75]$ & $0.2826[75]$ & $0.1889[75]$ & $0.2359[75]$ \\
\hline
\end{tabular}

Stars refer to level of significance, ${ }^{*}: 10$ per cent, ${ }^{* *}: 5$ per cent. ${ }^{* * *}: 1$ per cent 


\section{ANNEX 1. Comparison of the sample with the industry's structure}

Structure of the German asset management industry - by assets under management

Structure of data sample:

$\mathrm{H}_{0}$ : no difference ${ }^{1)}$

- by assets under management $-0.325(0.745)$

Structure of the German asset management industry - by company size ${ }^{2)}$

Structure of data sample:

Small player

[12]

5

5

Medium player

13
Big player

[8]

- by company size $e^{2)}$

8

$\mathrm{H}_{0}$ : no difference ${ }^{3)}$

$2.981(0.225)$

Participation in the survey:

Pearson correlation coefficient with company size (by asset under management, $p$-value in parentheses)

- by number of questionnaires per company

$$
0.472^{* * *}(0.001)
$$

The market data is based on the annual report of the German investment and asset management association (BVI) as of 2002.

1) The table gives the $z$-value of the Mann-Whitney U-test with the p-value in parentheses.

2) Here we focus on the company size of BVI member firms (ex those managing special funds only). The groups are clustered as follows: small players (mutual fund market share $<0.1 \%$ ), medium players (mutual fund market share $<=2.5 \%$ ), and big players (mutual fund market share $>2.5 \%$ ) with numbers given in squared bracket.

3) The table gives the test statistic of the chi-square test with the p-value in parentheses.

Stars refer to level of significance, ${ }^{*}: 10$ per cent, ${ }^{* *}: 5$ per cent. ${ }^{* * *}: 1$ per cent 